\title{
Corrosion of Copper in Mound's Single-Pass Potable Water Systems
}

Patrick M. Schleitweiler and Pameia S. Miller

Issued: December 7, 1990

\section{MOUND}

operated by

ELEG MOUND APPLIED TECHNOLOGIES

P.O. Box 3000. Miamisburg. Ohio 45343-3000

for the

U. S. DEPARTMENT OF ENERGY

Contract No. DE-AC04-88DP43495 


\section{Contents}

\section{Page}

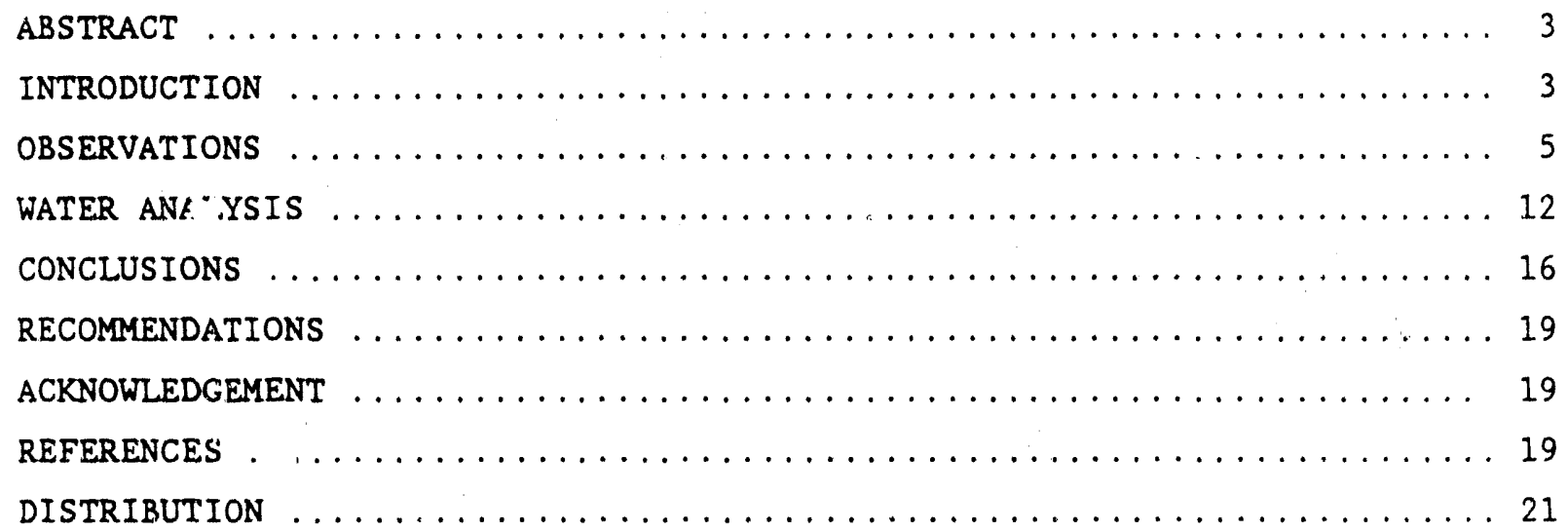




\begin{abstract}
An increase in the number of copper plumbing failures at Mound prompted a thorough analysis of the failed components. Most of the components were elbow joints. All of these parts exhibited the same type of accelerated deterioration. The failed parts were analyzed optically and by scanning electron microscopy. Water chemistry, solder, and soldering fluxes were evaluated to determine their possible roles in the accelerated attack. Cross-sectioning of the elbow joints revealed residual soldering flux and cutting burrs on the inside of the elbows. Water analysis showed Mound's water was rated as corrosive. Recommendations for improved workmanship and design are presented. Testing of potable water at a regular basis was also recommended.
\end{abstract}

\title{
Introduction
}

Intermittent failure of copper water lines has been a problem at Mound over the years. A rash of such failures between 1967 and 1972 resulted in an investigation of approximately 319 failed pipes. The committee that was appointed to study this problem completed an extensive copper corrosion report [1] which concluded that the failures resulted from erosion corrosion caused by poor water quality.

More recently, a dozen or more failures occurred between April and December of 19.39. Although these failures do not compare in number to those previously recorded from 1967 to 1972, they did alert us to potentially costly problems that can be corrected before acute situations arise. Undetected leaks can produce considerable damage and equipment downtime. Because the plumbing in Mound buildings is typically located overhead, above acoustica! drop ceilings, both the cost of plumbing repair and the potential for serious damage and equipment loss is high.

Two undetected leaks during the last eight months of 1989 are good examples of the kind of damage that can be caused by corrosion. The first one occurred in April over a weekend, soaking a new Auger surface analysis instrument waiting installation. Fortunately, the equipment was still in its 
packing material and was not seriously damaged. This incident raised questions about the copper plumbing at Mound and the potential for costly equipment loss. The second notable failure happened over Thanksgiving Day weekend in November 1989. A pinhole leak in a copper elbow flooded a $\$ 500,000$ gas chromatography mass spectrometer. The damage is still being determined.

Copper corrosion, in general, has been thoroughly studied and is well understood [2-6]. Copper is a corrosion-resistant metal used extensively to carry potable water in both commercial and residential applications. Good mechanical workability and ease of soldering, as well as comparatively low cost, make it well-suited for potable water plumbing. Most of the water lines at Mound are copper. All of the failures evaluated were in copper pipes or elbows.

Copper pipes and fittings are susceptible to degradation by mechanical wear processes. Impingement attack occurs when high velocity turbulent water abrades the copper surface, stripping away its protective oxide. Entrained particles or bubbles accelerate this process. Abrupt changes in direction, or features that produce low pressure regions or localized high velocity turbulence, can result in impingement attack. Geometric changes such as elbows naturally lend themselves to increased turbulence, thus promoting premature failure by erosion.

Joining copper pipes and fittings for potable water plumbing is most commonly done by soldering. Preparation of the joint includes using an aggressive flux to clean the areas to be joined. This can activate the copper surface by removing the protective oxide film.

This report summarizes all data and observations recorded during the recent investigations of copper plumbing failures. This includes: optical and electron optic observations of failed copper pipe, water analysis, and solder and solder flux analysis. 


\section{Observations}

The majority of analyzed failures were copper elbows. Three perforations, however, occurred in straight piaces of copper pipe several inches fxom the nearest elbow. Table 1 lists reported failures. All components were from continuous flow, single pass water systems. Other potable water systems at Mound were not affected. Most of the components submitted for analysis were from E- and DS-Buildings. This was because trades personnel in these areas were instructed to retain the failed parts. Therefore, the true extent of erosion damage throughout Mound's water systems is not known. However, similar failures were reported in other buildings, indicating these problems to be plant-wide.

Pin-hole leaks were found in the failed copper pipes and elbow joints. Prior to November, failed parts were removed during repair by desoldering. The resulting re-flow of solder and excessive heating limited the amount of useful informaticn that could be obtained by inspecting the desoldered parts. In November and December, falled parts were removed by cutting. These provided more detailed information in the failed region. Contaminants and physical configurations were left undisturbed in the cut parts, giving a more complete understanding of the failures.

Note (Table 1) that erosion corrosion was found in copper pipes of different diameter. No correlation could be made between the pipe diameter and the failure.

\section{Straight Pipe Failures}

The first straight pipes that were examined exhibited signs of classical erosion corrosion, with horseshoe-shaped grooves and undercut pits characterizing the failures. The development of an erosion pit within a pipe is schematically depicted in Figure 1. In the early stages, an obstruction alters the flow of water against the wall (A). The turbulence on the upstream side of the obstruction erodes away the pipe wall (B). As the erosion progresses, a "golf tee" is formed (C). The stem of the tee is finally worn away, and a horseshoe-shaped pit results (D). 
Table 1 - COPPER PLUMBING FAILURES ANALYZED

Date Location Type of Component Comments

\begin{tabular}{|c|c|c|c|}
\hline $4 / 89$ & $E-B I d g$ & Elbow $1 / 2$-in. & 1 yr of service \\
\hline $5 / 89$ & DS - Bldg & Elbow $3 / 4$-in. & $\begin{array}{l}18 \text { months of } \\
\text { service }\end{array}$ \\
\hline $5 / 89$ & DS - B1dg & Elbow $3 / 4$-in. & $\begin{array}{l}\text { same area as } \\
\text { above }\end{array}$ \\
\hline $9 / 89$ & DS - Bldg & Elbow $3 / 4$-in. & \\
\hline $10 / 89$ & DS - Bldg & Elbow 2 -in. & 2 -in. mainline \\
\hline $11 / 89$ & DS-Bldg & Straight 1 -in. & pin hole in wall \\
\hline $11 / 89$ & $E-B 1 d g$ & Elbow $1 / 2$-in. & 5 yr of service \\
\hline $11 / 89$ & $E-B I d g$ & Elbow $1 / 2$-in. & $\begin{array}{l}\text { adj to failed } \\
\text { elbow }\end{array}$ \\
\hline $12 / 89$ & DS - Bldg & Straight $3 / 4$-in. & pin hole in wall \\
\hline $2 / 90$ & $E-B l d g$ & Elbow $1 / 2$-in. & $\begin{array}{l}\text { another E } 112 \\
\text { failure }\end{array}$ \\
\hline $2 / 90$ & $E-B I d g$ & Elbow 1 -in. & same $1 a b$ as above \\
\hline $2 / 90$ & DS - BIdg & Elbow $3 / 4$-in. & desoldered \\
\hline $3 / 90$ & Guard Post I & Straight 1 -in. dia. & pin hole in wall \\
\hline
\end{tabular}

The deepest part of the pit is on the upstream side of the obstruction. This obstruction can come from a variety of sources (for example, a mineral

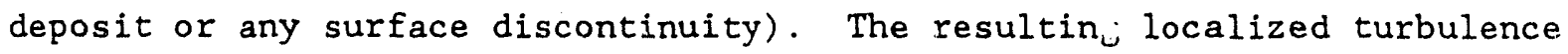
and increased flow rates continue accelerating the erosion process. When particles or entrained gas bubbles are part of the flow, the abrasive action of the liquid media is increased.

Figure 2 shows a section of straight pipe with the telltale signs of erosion. The flow direction of the water is indicated with the arrow. The open end of the crescent horseshoe-shaped erosion groove is downstream of the obstruction. The shape of the grooves was consistent with the direction of the water flow in these pipes. 
A higher magnification view of one of the erosion pits is shown in Figure 3 . The horseshoe-shaped pit easily seen. The blue-green scale appears to be sitting on top of a golf-tee as its support is worn away. The arrow indicates flow direction. The deep side of the pit is on the upstream side of the obstruction, which is consistent with the hydraulics depicted in Figure 1.

The blue-green scale visible in Figures 2 and 3 was analyzed using energy dispersive spectroscopy (EDS). Typical spectra axe shown in Figures 4 and 5. Iron, chlorine, phosphorus, and some calcium accompany copper in the spectra. These elements are present in the water both naturally and through water treatment.

\section{Copper Elbow Failures}

The largest number of plumbing failures have occurred in copper elbows. Figures 6 and 7 are cross-sections of failed elbows that were cut from the plumbing. Close examination of all the elbows revealed the same type of deterioration. Each exhibited deep grooving where the inlet and outlet pipes terminated in the elbow. In nearly all cases, the localized thinning of the elbow led to a perforation on the upstream side of the connection. The small arrows in the figures indicate the direction of flow; the large arrows highlight the perforation.

Heavy scale buildup is visible in Figure 6 . It is apparent that the scale is broken and discontinuous. Again, as in the straight pipe, EDS analysis indicated that the scale is composed of iron, calcium, phosphorous, and chlorine. Pipe cutting burrs were observed in nearly all of the elbows examined. The burrs normally result when tube cutters are used to cut the copper pipes to length. Figure 8 clearly shows the lip from the cut pipe. Good workmanship practices include a reaming operation to eliminate burrs after the pipe is cut, thereby eliminating flow obstruction [7].

Residual soldering flux was found in four of the elbovs. The flux was found in the groove on the front edge of the incoming and outgoing pipe as shown in 

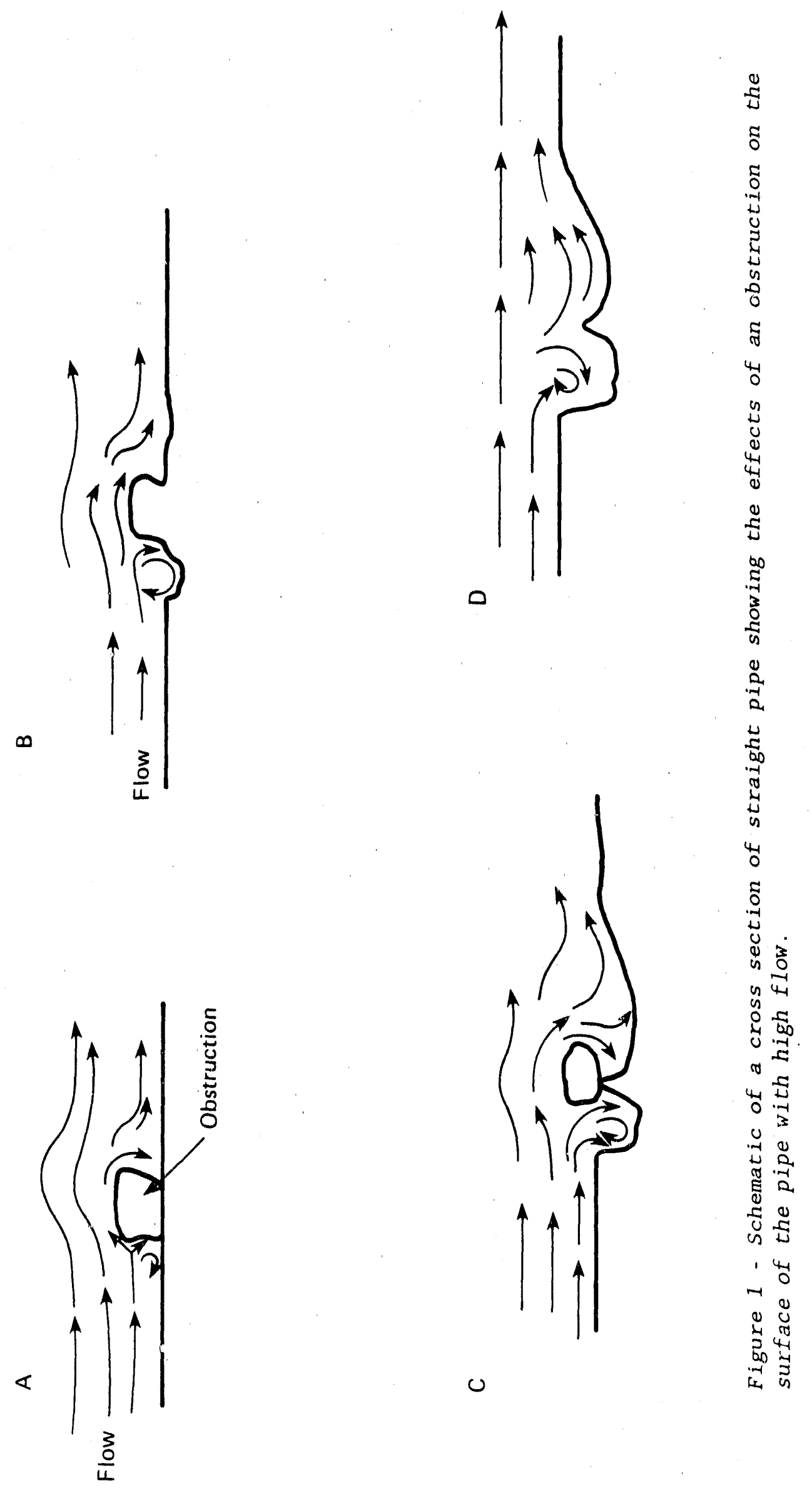


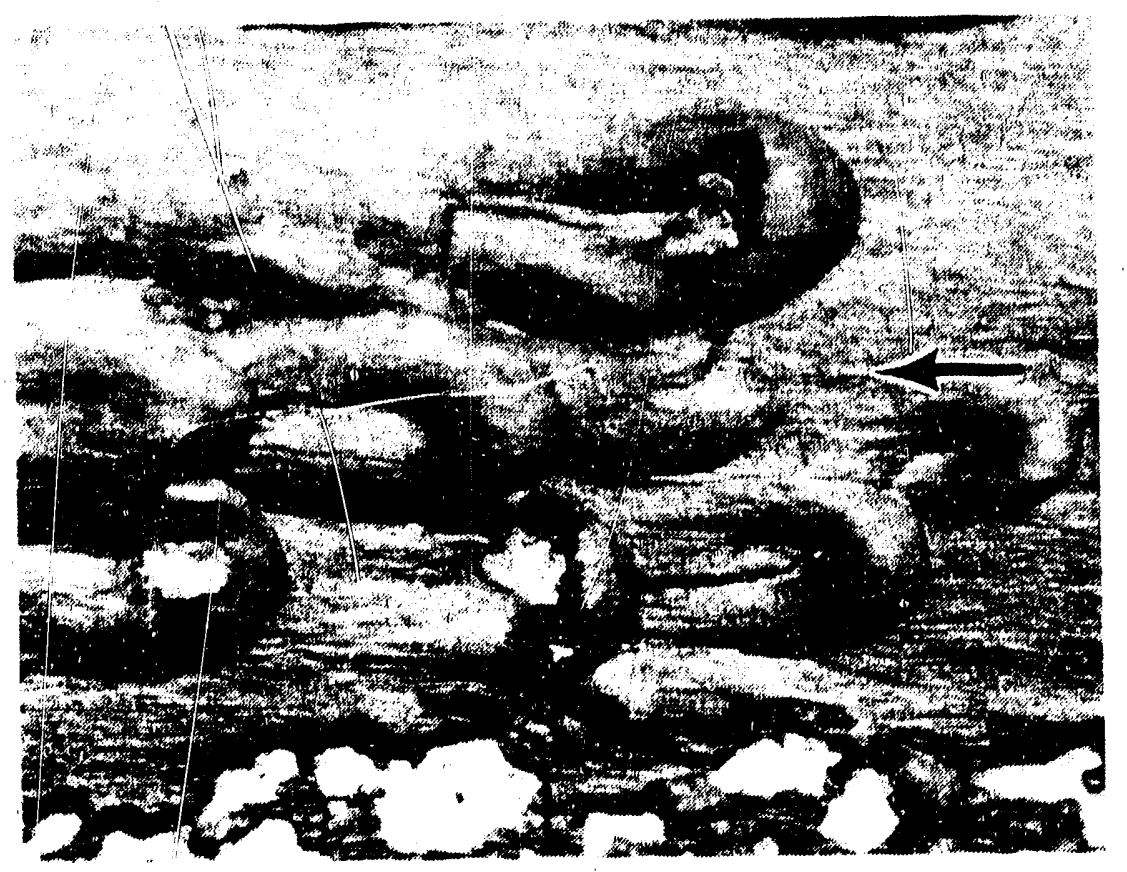

Figure 2 - Erosion corrosion found in a failed straight section of pipe. The arrow indicates direction of flow.

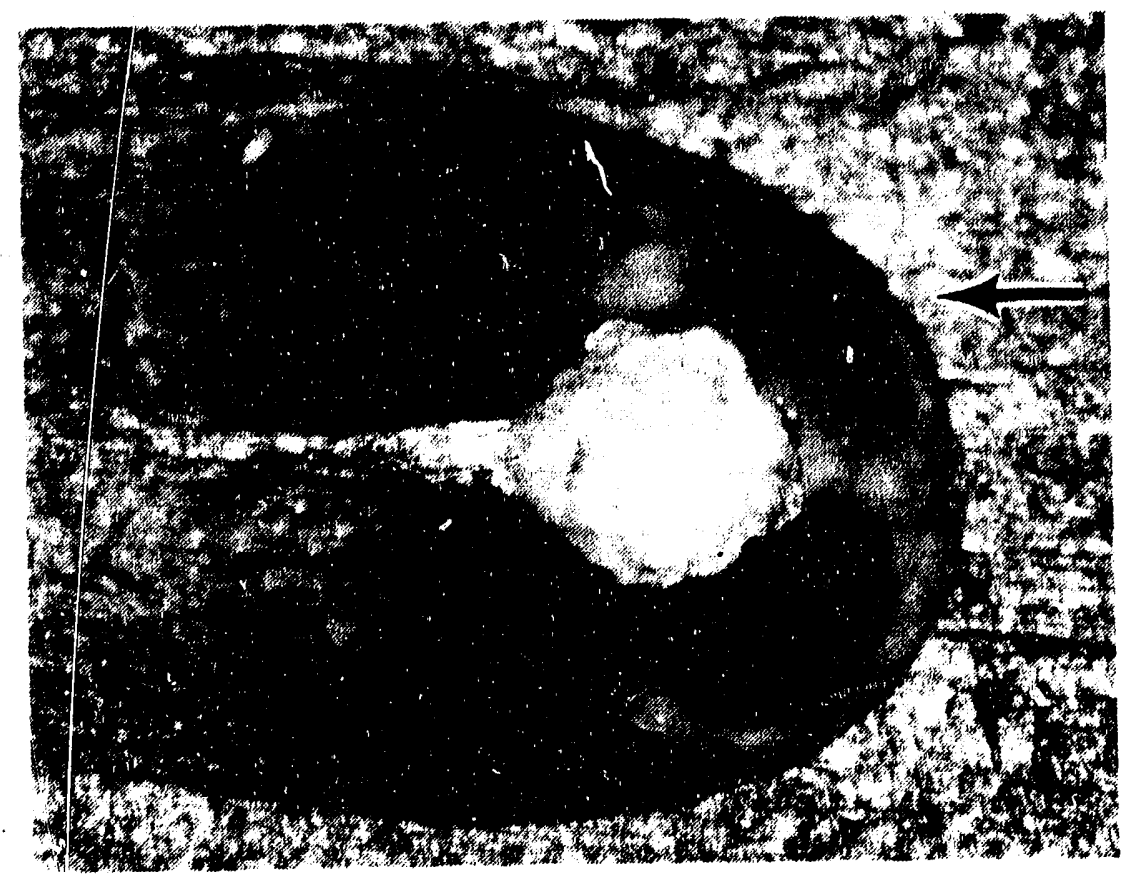

Figure 3 - Horseshoe-shaped erosion pit. Arrow indicates direction of flow. 


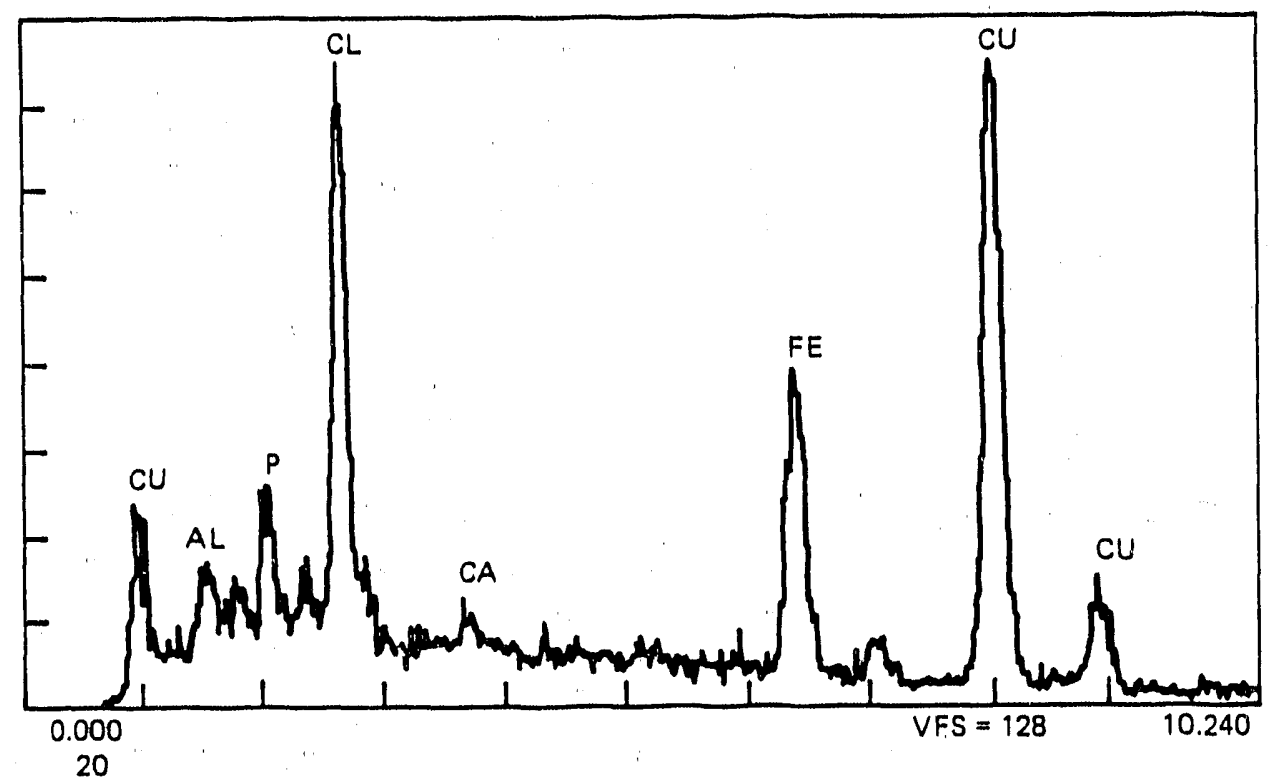

Figure 4 - Energy Dispersive Spectrum (EDS) of blue-green scale on failed parts. Note the strong Iron (Fe) and Phosphorous ( $P$ ) peaks.

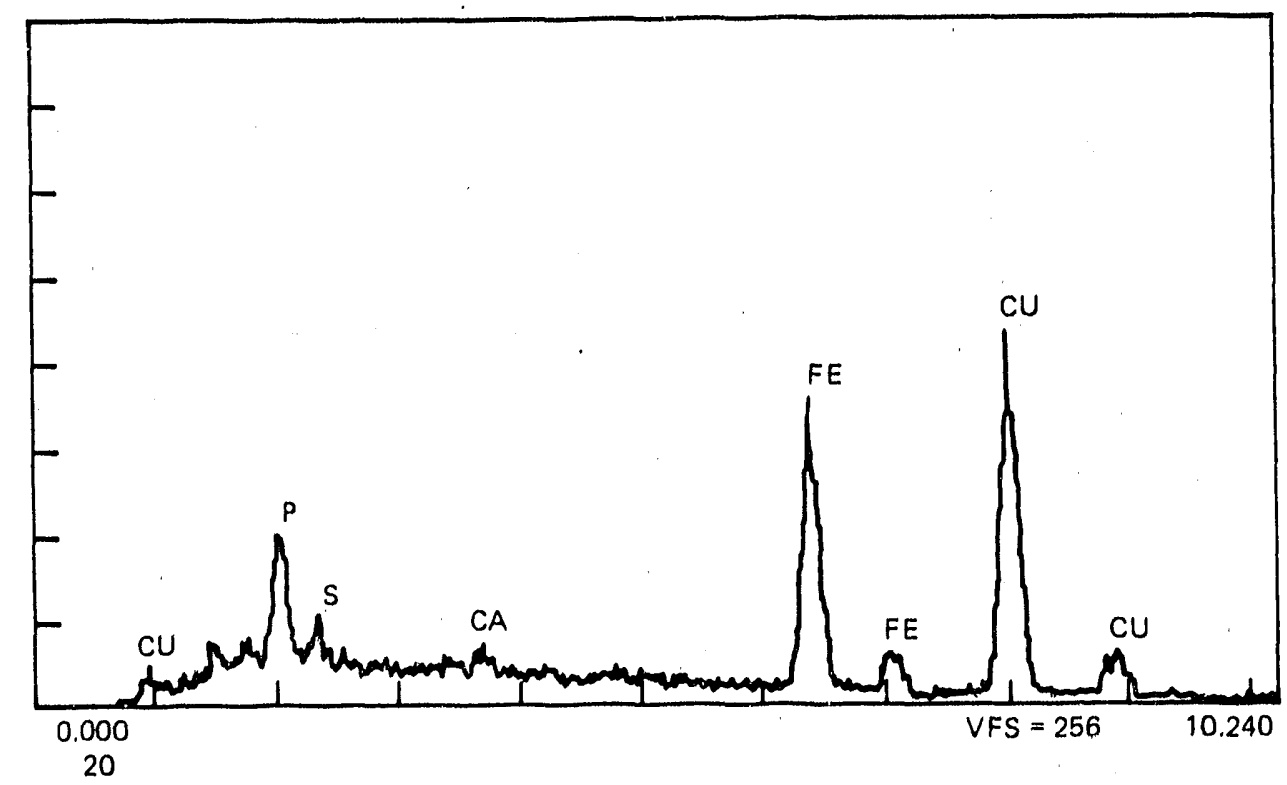

Figure 5 - Energy Dispersive Spectrum (EDS) of blue-green scale on failed components. Note strong Chlorine (C1) and Iron (Fe) peaks. 


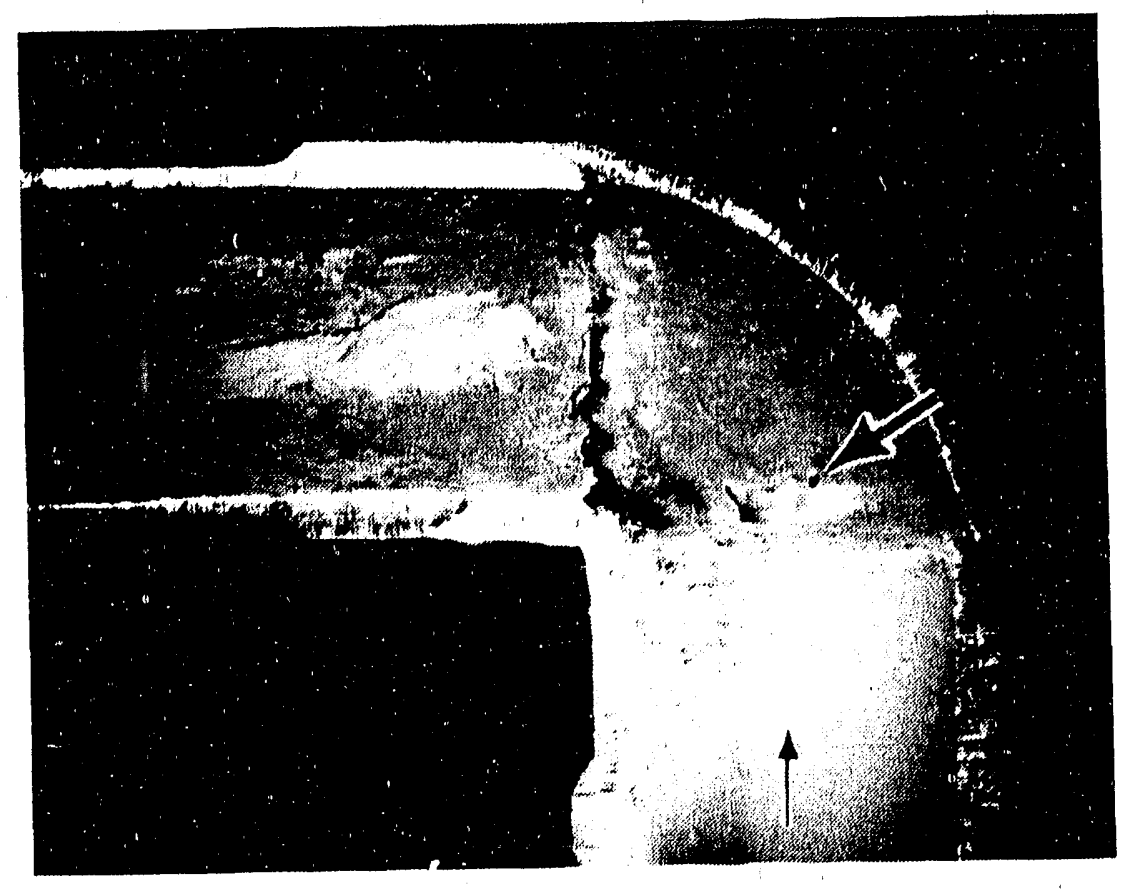

Figure 6 - Cross section of a 1/2-in. diameter copper elbow. Small arrow indicates flow direction. Large arrow shows perforation.

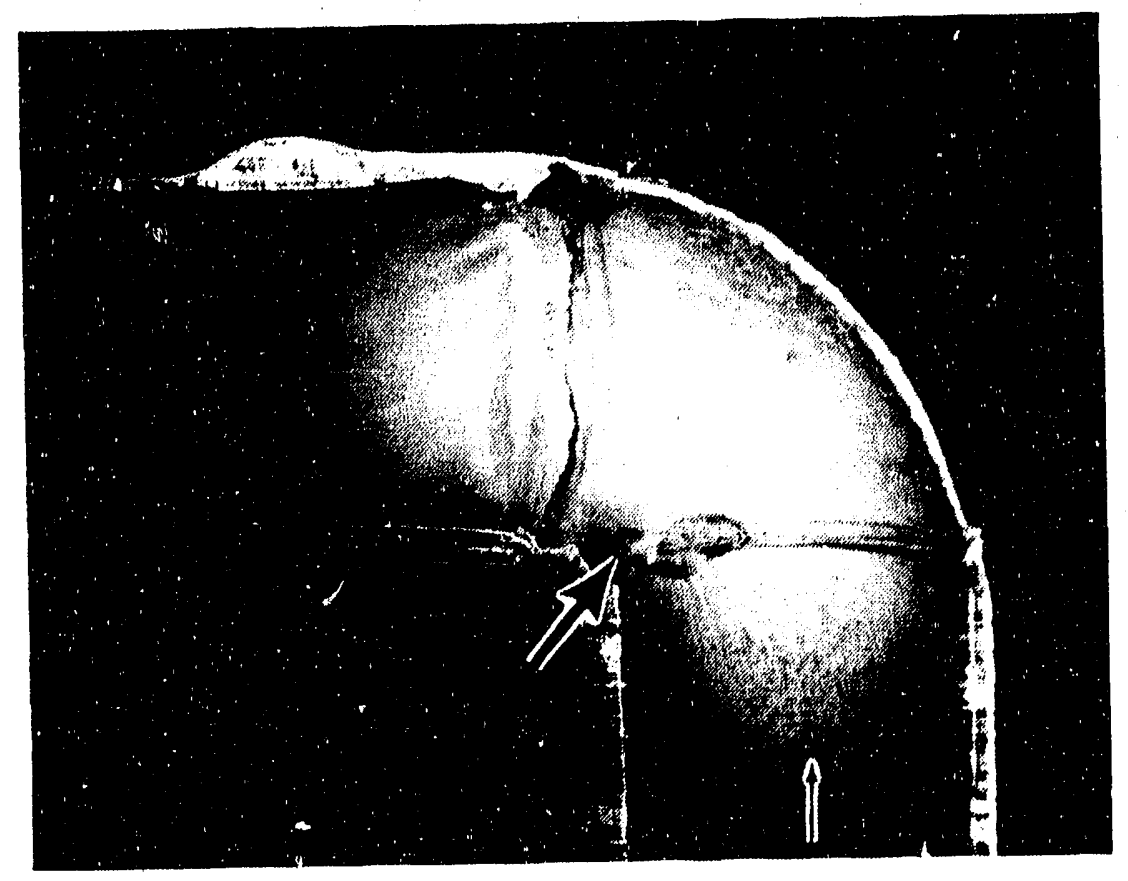

Figure 7 - Cross section of a 3/4-in. diameter copper elbow. Small arrow indicates flow direction. Large arrow shows perforation. 
Figure 9. Preparation of the solder joilt includes using an aggressive flux to clean the areas to be joined. Flux activates the surface by removing the oxide film. Fourier Transform Infrared Spectroscopy (FTIR) identified the flux as Oatey No. 5 soldering paste. The flux remained in the elbow even after years of service.

\section{Water Analysis}

The chemistry and flow rate of water is significant when erosion corrosion exists. Water chemistry was sampled from four locations in the plant. The results of the analysis are shown in Table 2. Total dissolved solids (TDS) appeared high and had different values at various locations. Analysis of the TDS using Energy Dispersive Spectrometry (EDS) indicated that the solid was sodium and chlorine. The result was the same for all of the samples. Normally, $\mathrm{pH}$ should be around 7.1. As shown in Table 2, there was some deviation from this value.

The scaling tendency of the water was determined by a calculation of the calcium carbonate saturation. The result of this calculation is known as the Langelier index. (Although the Langeliex index was originally based on data for mild steel corrosion, it can also be used to categorize Mound's potable water.) The Langelier index considers TDS, $\mathrm{pH}$, alkalinity, and csilcium hardness (calculated by methyl orange and total alkalinity). If the index is 0 , the water is in cherical balance. If the index is positive, there exists a tendency for calcium carbonate deposition, which will protect the copper. If the index is negative, calcium carbonate does not precipitate, and the probability of corrosion increases as the index becomes more negative. A separate analysis of the water from E-building was performed using proper techniques to provide Langelier values. This analysis showed 520 ppm TDS, $>17 \mathrm{ppm}$ calcium hardness, and $340 \mathrm{ppm}$ alkalinity at $\mathrm{pH} 6.9$ to 7.1 . The Langelier index for this condition is -1.3. This value indicates that the water could cause severe significant corrosion [8].

The flow rate of the water is significant when evidence of erosion corrosion exists. The flow rates in several areas in $E$. an $R$-Building were obtained 


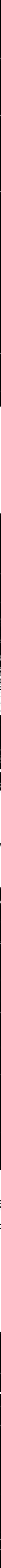




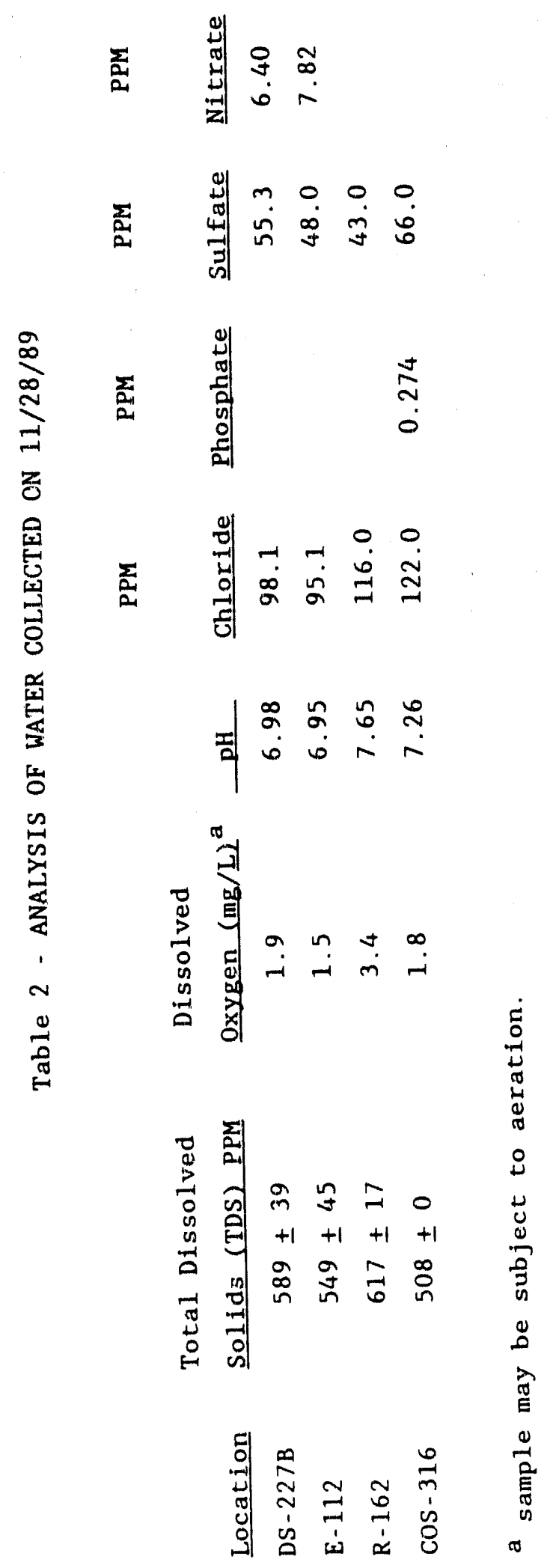


using a three-gallon bucket and a stopwatch. The pipe diameter at each location was determined and a rough approximation of the flow rate in gallons per minute was obtained. An average rate of about $7 \mathrm{ft} / \mathrm{s}$ was recorded. The readings were taken from lab sinks in the areas of the plant that had experienced copper plumbing corrosion; however, these lines do not carry continuously flowing water. It is clear that the flow rate data obtained in this manner can only be used to approximate the flow rates experienced by the failed components.

\section{Solder and Flux observation}

Chemical analysis was done on three of the soldering fluxes commonly used at Mound. Stay Clean is a clear liquid flux. It was analyzed and had a chloride concentration of 32.68. Oatey No. 5 and Nokorode are paste fluxes that are petroleum based and insoluble in water. These had 14.0 and 11.88 chloride concentration, respectively. Zinc chloride is the active ingredient in the paste fluxes.

The residual paste flux that remained in the elbows (Figure 9) was very resistant to the continuous flow of water in the elbow. Flux was also found to be present in a straight section failure. An erosion pit that led to a pin hole leak in the side of a straight pipe is shown in Figure 10. The white gel is residual soldering paste that affixed itself to the side of the pipe. This section of pipe showed very little evidence of widespread erosion corrosion.

In 1986 a federal regulation was instituted requiring that all solder used in a potable water system be lead-free. Two pieces of solder used in water pipe assembly and repair at Mound were chemically analyzed. The results are presented in Table 3. There were no indications that the wrong type of solder was used. The accelerated corrosion of the copper pipes was not linked to the solder. 


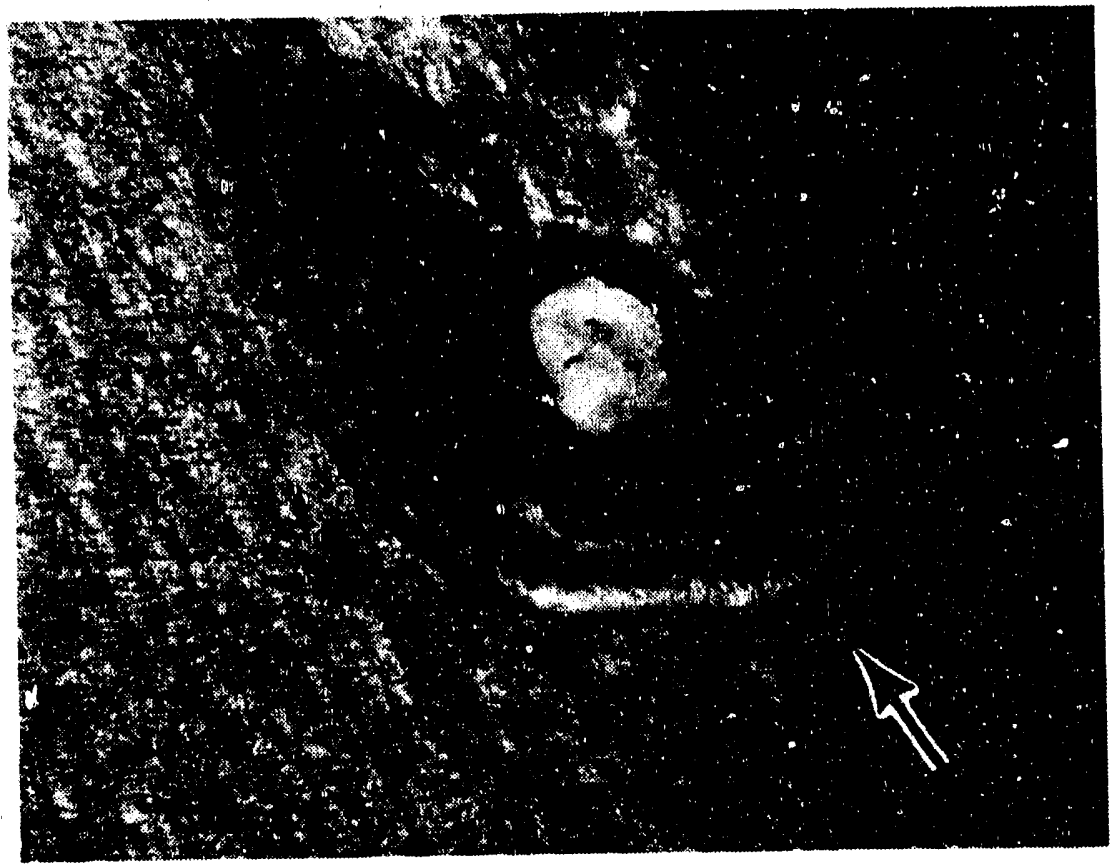

Figure 10 - Straight pipe from DS Room 214 with residual solder adhering to the wall of the pipe. The arrow indicates flow direction.

\section{Conclusions}

Erosion corrosion is the principal contributor to the failure of the copper plumbing examined at Mound over the last 12 months. Several factors have contributed to the accelerated failure of the copper. It is difficult to separate the factors and identify one particular cause of failure. Erosion, the ultimate cause of failure, was an effect of the impingement of particulates and turbulent flow through the copper elbow and pipes. The tendency of the water to be corrosive, as indicated by the Langelier scaling index, is significant. Some of the copper examined during the course of this investigation had calcium carbonate and calcium phosphate scale layers. The discontinuous nature of this protective layer i: likely due to inconsistencies in water chemistry. Changes in water chemistry could allow a film formation followed by a film breakdown. The impingement of particulates 
Table 3 - COMPOSITION OF SOLDERING ALLOYS

STAY SAFE

\begin{tabular}{ccc}
\multicolumn{2}{c}{ Ag Brazing Alloy } & $95 \mathrm{Sn} \mathrm{Sb}$ \\
Element & Amount (8) & Amount (z) \\
$\mathrm{Cu}$ & 0.45 & 0.09 \\
$\mathrm{~B}$ & $<0.005$ & $<0.005$ \\
$\mathrm{Fe}$ & 0.03 & $<0.005$ \\
$\mathrm{Mg}$ & $<0.005$ & $<0.005$ \\
$\mathrm{Na}$ & $<0.005$ & $<0.005$ \\
$\mathrm{~Pb}$ & $<0.05$ & 0.07 \\
$\mathrm{Si}$ & $<0.005$ & $<0.005$ \\
$\mathrm{Sn}$ & major $>908$ & Major $>908$ \\
$\mathrm{Zn}$ & 1.07 & 0.005 \\
$\mathrm{Ag}$ & 0.35 & 0.03 \\
$\mathrm{Sb}$ & 2.82 & 4.67
\end{tabular}

and turbulence in the copper pipes can also break down protective films. The presence of a discontinuous coating accelerates the erosion by increasing turbulence. Turbulence increases as the surface of the metal changes. The discontinuous scale, therefore, can produce high localized flow rates that can dramatically affect the erosion of the copper. This was seen in both straight pipe and in elbows.

The deep eroded ruts found in the elbow cross-sections at the base of the inlet and outlet pipes were likely the result of two conditions: the presence of pipe cutting burrs, and residual flux in the solder joint.

Most of the elbow showed remains of pipe cutting burrs. It is likely the remains were eroded away for the others. The burrs cause turbulence and a venturi effect. The effects of these differences in water velocity are more pronounced in metals that form a protective coating like copper. Usually simple lamellar for straight-line flow causes no problems. Problems do occur, however, when an obstruction or surface discontinuity appears and 
turbulent flow develops. Thus, cutting burrs accelerated the erosion in the elbows.

The chlorine in the residual flux found in some of the elbows provided a locally corrosive environment. In addition, the insolubility of the petroleum-based gels used in the flux may have limited the supply of oxygen to the area, forming a differential aeration cell. This promoted corrosion.

To combat the effect of residual flux, contractors are required to flush a neutralizing agent through new copper plumbing installations before they are put into use. This is easier to do for new, complete installations. It is not normally done for repairs and smaller installations at Mound. This can lead to future problems.

The tenaciousness with which the paste flux stays in the solder joints is surprising. The flux paste was found in elbows that had been in service for more than 2 years. The flux found in the straight pipe, Figure 10, was more than six inches away from the nearest solder joint. It appeared to have have come from an upstream solder joint and attached itself to the side of the pipe. This deposit of flux acted as an obstruction, accelerating erosion in the same fashion as discontinuous scale or any foreign deposit.

Water chemistry also contributed to the accelerated failure of the copper pipes that were analyzed. The Langelier index for the sampled water indicated a tendency for the water to be corrosive. Mound has increased the additions of chlorine to the water in recent years to comply with EPA requirements. The chlorine concentration is not factored into the Langelier index, which is a shortcoming when evaluating copper corrosion.

The flow rates in the labs were approximated at $7 \mathrm{ft} / \mathrm{s}$. This is within design engineering quidelines. However, corrosion protection references recommend a maximum of $4-5 \mathrm{ft} / \mathrm{s}[7]$. 


\section{Recommendations}

The following recommendations were submitted in response to a formal investigation of a copper elbow failure in E-112 on November 27, 1989.

1. Analyze flow rates in E- and DS-Building. Adjust as necessary.

2. Instruct pipefitters to carefully prepare pipe ends and limit the use of flux.

3. Monitor water quality using Langelier scaling index to ensure proper softening.

4. Streamline piping to minimize flow restrictions.

5. Evaluate the use of a more exosion-resistant copper alloy for elbows.

\section{Acknowledgements}

The authors would like to thank M. K. Hershey, W. M. Preston, and V. L. George for their water analysis. The authors would also like to thank Dr. R. S. Carlson, who used Fourier Transform Infrared Spectroscopy to identify the soldering flux.

\section{References}

1. T. L. Jameson, Copper Corrosion Report, Monsanto Research Corporation, Miamisburg Ohio, July 1972.

2. L. L. Shreir (ed.), "Corrosion of Metals and Alloys," Vol. 1., pp. 4.27-4.58, Corrosion, John Wiley \& Sons, New York, 1963.

3. G. Butler, H. C. K. Ison, Corrosion and Its Prevontion in Waters, Ist Ed., Reinhold Publishing Co., New York, 1966. 
4. H. H. Ulig, Corrosion and Corrosion Control, 2nd Ed., John Wiley \& Sons, New York, 1971, pp. 17-36, 322-333.

5. M. G. Fontana, N. D. Green, Corrosion Engineering, 2nd Ed., McGraw Hill, New York, 1978, pp. 172-174.

6. "Corrosion," Vol. 13, ASM Metals Handbook, 9th Ed., ASM International, Metals Park, Ohio, 1987, pp. 610-640.

7. J. M. Cielewicz and P. A. Schweitzer, Corrosion and Corrosion Protection Handbook, Marcel Dekker Inc., New York, '1989, p. 130 .

8. R. S. Treseder (ed.), NACE Corrosion Engineer's Reference Book, 2nd Ed., National Association of Corrosion Engineers, Sept. 1980 , p. 70. 

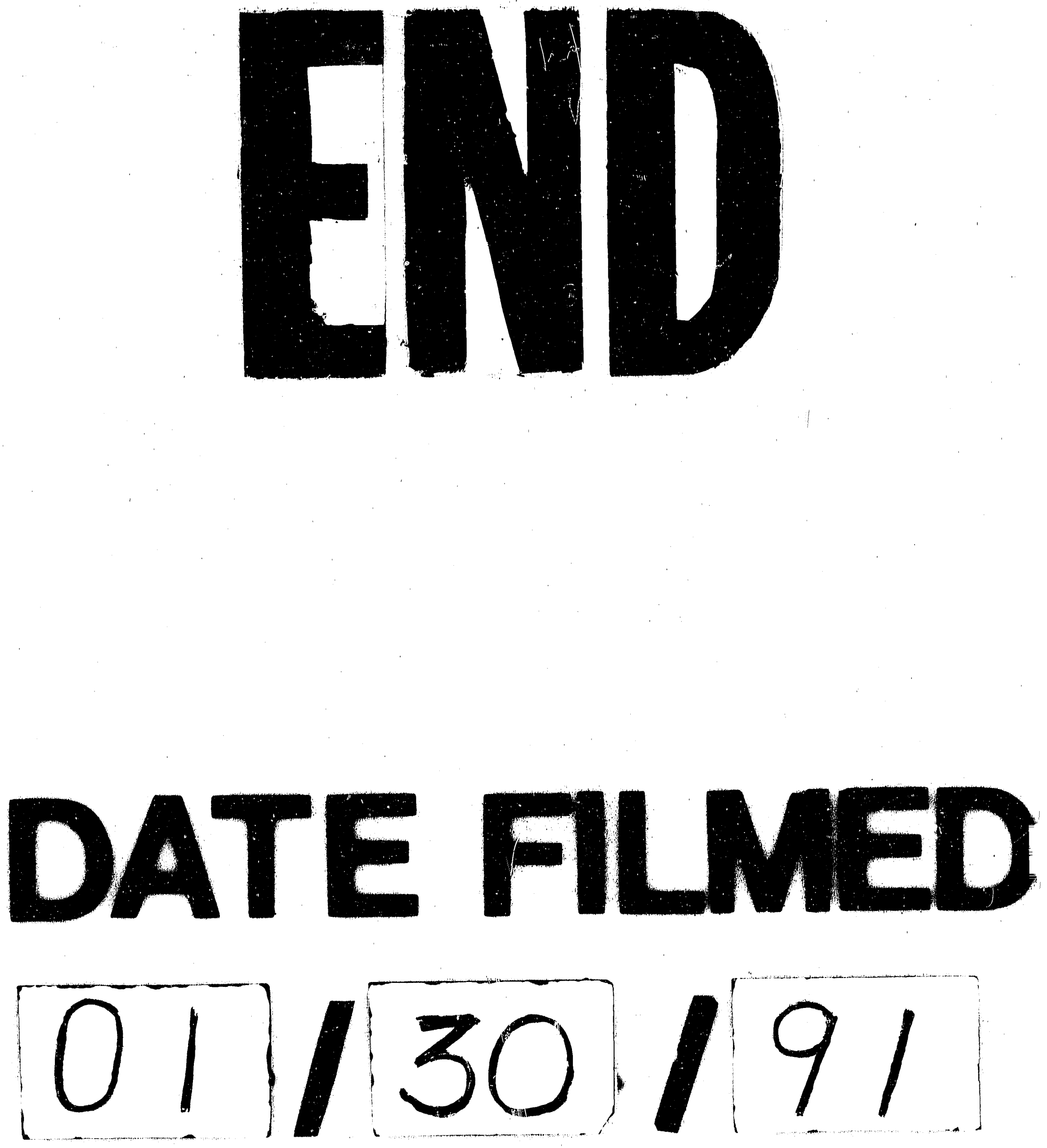
